Illinois State University

ISU ReD: Research and eData

Theses and Dissertations

$5-28-2019$

\title{
Childhood Sexual Abuse, Personality, and Risk Recognition
}

Emily M. Harms

Illinois State University, emharms6@gmail.com

Follow this and additional works at: https://ir.library.illinoisstate.edu/etd

Part of the Counseling Psychology Commons

\section{Recommended Citation}

Harms, Emily M., "Childhood Sexual Abuse, Personality, and Risk Recognition" (2019). Theses and Dissertations. 1139.

https://ir.library.illinoisstate.edu/etd/1139

This Thesis is brought to you for free and open access by ISU ReD: Research and eData. It has been accepted for inclusion in Theses and Dissertations by an authorized administrator of ISU ReD: Research and eData. For more information, please contact ISUReD@ilstu.edu. 


\section{CHILDHOOD SEXUAL ABUSE, PERSONALITY,}

\section{AND RISK RECOGNITION}

\section{EMILY M. HARMS}

\section{Pages}

The purpose of the study was to examine the influence of childhood sexual abuse (CSA) and personality in predicting risk recognition among college-aged women. Participants included 223 female undergraduate students at Illinois State University. Students were presented the opportunity to receive extra credit for participating in the study. Participants completed a demographics questionnaire, the Big Five Inventory, and the Personality Inventory for the DSM5 - Brief Form. Participants then read through a risk recognition vignette that was divided into 13 scenes and were asked to indicate when they were no longer comfortable in the situation and when they would leave the situation. Over a third of participants $(37.7 \%)$ reported a history of CSA and were placed in the CSA group. CSA was not related to higher response latency. CSA was found to be related to higher levels of negative affectivity, psychoticism, and disinhibition, as well as higher levels of neuroticism and lower levels of agreeableness. Neuroticism was significantly negatively correlated with risk recognition. Finally, psychoticism and neuroticism were significantly related to risk recognition when controlling for other variables. KEYWORDS: Childhood Sexual Abuse, Personality, Risk Recognition 
CHILDHOOD SEXUAL ABUSE, PERSONALITY,

AND RISK RECOGNITION

EMILY M. HARMS

A Thesis Submitted in Partial

Fulfillment of the Requirements

for the Degree of

MASTER OF SCIENCE

Department of Psychology

ILLINOIS STATE UNIVERISTY 
(C) 2019 Emily M. Harms 


\section{CHILDHOOD SEXUAL ABUSE, PERSONALITY,}

AND RISK RECOGNITION

EMILY M. HARMS

COMMITTEE MEMBERS:

Marla Reese-Weber, Chair

Jeffrey Kahn 


\section{ACKNOWLEGMENTS}

I would like to thank my committee, Dr. Marla Reese-Weber and Dr. Jeffrey Kahn, for their support and guidance throughout the entire process. I would also like to thank my friend,

Jordan Marshall, for all of the help collecting data and the support she has provided over the last few years.

E. M. H. 


\section{CONTENTS}

$\begin{array}{lll}\text { Page } & \end{array}$

ACKNOWLEDGMENTS

CONTENTS

TABLES

CHAPTER I: THE PROBLEM AND ITS BACKGROUND 1

CHAPTER II: LITERATURE REVIEW

Childhood Sexual Abuse $\quad 3$

Risk Recognition $\quad 8$

$\begin{array}{ll}\text { Personality } & 11\end{array}$

$\begin{array}{ll}\text { The Current Study } & 17\end{array}$

CHAPTER III: RESEARCH METHODOLOGY 21

$\begin{array}{ll}\text { Participants } & 21\end{array}$

$\begin{array}{ll}\text { Instruments } & 22\end{array}$

$\begin{array}{ll}\text { Demographic Questionnaire } & 22\end{array}$

$\begin{array}{ll}\text { Childhood Sexual Abuse } & 22\end{array}$

$\begin{array}{ll}\text { Personality } & 23\end{array}$

$\begin{array}{ll}\text { Risk Recognition } & 24\end{array}$

$\begin{array}{ll}\text { Procedure } & 25\end{array}$

CHAPTER IV: RESULTS 26

CHAPTER V: DISCUSSION

Limitations and Future Directions 38

$\begin{array}{ll}\text { Strengths and Conclusions } & 39\end{array}$ 
$\begin{array}{ll}\text { REFERENCES } & 41\end{array}$

APPENDIX A: INFORMED CONSENT

APPENDIX B: DEMOGRAPHIC QUESTIONNAIRE

APPENDIX C: DEBRIEFING STATEMENT

APPENDIX D: VIGNETTE

APPENDIX E: STUDY PROCEDURE 


\section{TABLES}

Table

2. T-statistics, Means, and Standard Deviations for Personality Characteristics in CSA and Non-CSA Groups

3. Relationship between Risk Recognition, Negative Affectivity, Detachment, Antagonism, Disinhibition, and Psychoticism

4. Relationship between Risk Recognition, Extraversion, Agreeableness, Conscientiousness, Neuroticism, Openness to Experience, and CSA 


\section{CHAPTER I: THE PROBLEM AND ITS BACKGROUND}

Globally, childhood sexual abuse has a prevalence rate of about 12\% (Stoltenborgh, van Ijzendoorn, Euser, \& Bakermans-Kranenburg, 2011). In a meta-analysis including a sample of over 9 million individuals, about $18 \%$ of females and $8 \%$ of males report a lifetime history of CSA (Stoltenborgh et al., 2011). In the United States, between 20-30\% of women and 4-76\% of men report a history of childhood sexual abuse (Dube, Anda, Whitfield, Brown, Felitti, Dong, \& Giles, 2005). Boys are likely to be sexually abused by both men and women, while girls are much more likely to be sexually abused by men. Dube et al. (2005) defined mild CSA as contact only (i.e., touching, fondling) and severe CSA as attempted or completed intercourse. The results indicated that $16 \%$ of men and $25 \%$ of women reported some form of CSA. Of those reporting CSA, approximately $42 \%$ of men and $23 \%$ of women reported severe CSA.

Finkelhor (1984) defines childhood sexual abuse as any sexual contact with a child that occurs when the offender is significantly older than the child, is in a position of authority over a child, or the actions are perpetrated using violence or deceit. The most common scenarios in which CSA occurs are between adults and unrelated prepubescent children, between parents and their children, or using sexual force and violence against children (Finkelhor, 1984).

Childhood sexual abuse has been found to be related to a variety of negative outcomes, including mood disorders, impaired judgement, personality disorders, revictimization, and suicide (Finkelhor \& Browne, 1985). A history of CSA is also related to increases in response latency in adulthood, meaning that individuals with a history of CSA are less likely to respond to danger cues during risky experiences (Walsh, DiLillo, \& Messman-Moore, 2012). Researchers have also found a relationship between childhood sexual abuse and adult personality characteristics (Allen \& Lauterbach, 2007; Moran et al., 2011). To date, however, there is a lack 
of research regarding the influence that CSA and adult personality characteristics combined have on risk recognition. The purpose of the present study was to investigate the relationship between CSA, personality, and risk recognition among college-aged individuals. 


\section{CHAPTER II: LITERATURE REVIEW}

\section{Childhood Sexual Abuse}

Finkelhor and Browne (1985) proposed a framework to highlight four traumagenic dynamics that result from CSA. The first dynamic, traumatic sexualization, occurs through developmentally inappropriate sexual exchanges. During the abuse, the child is repeatedly made to partake in sexual acts that are developmentally inappropriate in exchange for affection, attention, and gifts (Finkelhor \& Browne, 1985). Traumatic sexualization also occurs when a child's body parts are given distorted meaning by the offender, when children develop misconceptions about sexual behaviors, and when children associate memories of the abuse with all sexual activity. As a consequence, the child learns that sex can be used as a token for manipulation, and this trauma can lead a child to behave in sexually inappropriate ways throughout childhood, adolescence, and adulthood (Finkelhor \& Browne, 1985). Traumatic sexualization can also vary in degree of intensity, depending on the severity of the trauma experienced. For example, children who are forced to actively participate in sexual activities are likely to be more negatively affected than children who are passive participants in the acts (Finkelhor \& Browne, 1985). Age also plays an important role in the degree of traumatic sexualization, as a child who is older and has greater awareness of the events occurring might be more affected by the experience than a child who is unaware of the severity of the situation (Finkelhor \& Browne, 1985). The lasting effects of traumatic sexualization include preoccupation with sex, sexual aggression, risky sexual behaviors, flashbacks to abuse, negative body-image, and fear and revulsion toward intimacy and sex (Finkelhor \& Browne, 1985).

One example of traumatic sexualization is the development of distorted body image and eating disorders in children, adolescents, and adults. Among children ages 10-15, individuals 
with a history of CSA were more likely to report weight dissatisfaction, food restriction, and increased purging behaviors (Wonderlich et al., 2000). Kendler and colleagues (2000) found a significant association between CSA and bulimia nervosa in adulthood. In a study investigating the relationship between CSA and anorexia nervosa, researchers found that $48 \%$ of their participants reported a history of CSA, and individuals with anorexia nervosa- binge-purge subtype were significantly more likely to report a history of CSA than individuals with anorexia nervosa- restricting subtype (Carter, Bewell, Blackmore, \& Woodside, 2006).

As a consequence of traumatic sexualization, survivors of childhood sexual abuse may be more likely to engage in risky sexual behavior during adolescence (Fergusson, Horwood, \& Lynskey, 1997). Individuals with a history of severe CSA have higher rates of teenage sex, teenage pregnancy, unprotected sex, sexually transmitted diseases, multiple partners, and sexual assault (Fergusson et al., 1997). When controlling for other forms of child maltreatment including physical abuse, psychological abuse, and neglect, researchers have found that childhood sexual abuse is a unique predictor of risky sexual behavior among adult women (Senn \& Carey, 2010). Research also suggests that men with a history of CSA are more likely to engage in risky sexual behavior and alcohol and drug use in adulthood (Dilorio, Hartwell, \& Hansen, 2002).

A second dynamic is betrayal, which occurs when a child is abused by an individual that they had come to trust. This also occurs when victims of child abuse are disregarded by the adults that they confide in about their abuse (Finkelhor \& Browne, 1985). Children have family members and other adults that they have learned to rely on throughout their life, and when they feel deceived by those individuals through the dynamics of childhood sexual abuse, feelings of betrayal can emerge (Finkelhor \& Browne, 1985). The effects of betrayal include dependency, 
impaired judgement, anger, hostility, and distrust. Antisocial personalities and delinquent behaviors are also related to the dynamic of betrayal (Finkelhor \& Browne, 1985).

Anger, a common consequence of betrayal, often manifests itself as chronic irritability, unexpected outbursts, and difficulty expressing such feelings (Briere \& Elliot, 1994). In childhood, anger is typically expressed through externalizing behaviors including fighting, bullying, and hurting other children. Likewise, in adulthood, survivors of CSA score higher than their non-abused peers on measures of anger and irritability. Survivors of CSA are more likely to perpetrate against children and women later in adolescence and adulthood (Briere \& Elliot, 1994).

Personality disorders are a common outcome for individuals reporting a history of childhood abuse or neglect and these disorders are related to the traumagenic dynamic of betrayal (Finkelhor \& Browne, 1985; Johnson, Cohen, Brown, Smailes, \& Berstein, 1999). Research suggests that individuals with a history of abuse are four times more likely to develop a personality disorder, even when controlling for age, parental education, and parental psychiatric disorders. Antisocial personality disorder and dependent personality disorder are two personality disorders that are significantly associated with childhood abuse and maltreatment. Antisocial personality disorder has been found to be significantly associated with childhood abuse, even when controlling for symptoms of all other personality disorders (Johnson et al., 1999).

The third dynamic, powerlessness, occurs when a victim is repeatedly taken advantage of by the offender (Finkelhor \& Browne, 1985). Factors that contribute to feelings of powerlessness include a victim's attempts to stop the abuse, feeling trapped in the situation, and repeated, unsuccessful attempts to tell other adults about their experiences. Severity of the abuse, like forcing the victim to participate in the abuse, can also intensify feelings of powerlessness 
(Finkelhor \& Browne, 1985). This powerlessness might lead a victim to experience symptoms like those related to posttraumatic stress disorder (PTSD), including fear, anxiety, hypervigilance, and phobias. Powerlessness is also related to symptoms of depression, poor coping skills, and suicidal behavior (Finkelhor \& Browne, 1985).

The traumagenic dynamic of powerlessness, resulting in fear and anxiety, can manifest in many forms. CSA and mood disorders such as depression and anxiety have been found to be related even after controlling for family history and social background (Fergusson, Horwood, \& Lynskey, 1996). Individuals with a history of CSA are also twice as likely to attempt suicide than individuals with no history of abuse. Individuals experiencing CSA with intercourse are more likely to attempt suicide than individuals reporting CSA with no intercourse (Dube et al., 2005). Powerlessness is also significantly associated with the development of complex PTSD (McLean \& Gallop, 2003). Specifically, individuals reporting early-onset abuse (age 12 or earlier) are more likely to develop complex PTSD than individuals reporting late-onset abuse (age 13 or later; McLean \& Gallop, 2003).

Stigmatization is the dynamic that refers to the guilt and shame that a victim of child abuse feels about the abuse that they have experienced (Finkelhor \& Browne, 1985). Specifically, stigmatization refers to the negative connotations associated with those experiences. These negative ideations are incorporated into the victim's identity by offenders, family members, and the community through victim blaming, secrecy, and shame. The severity of the stigmatization felt by the victim depends largely on the sense of responsibility the victim feels in the wake of their abuse. Victims made to feel alone and guilty are likely to feel much more stigmatization within their identities than those individuals who learn that they are not alone or are reminded that the abuse was not their fault (Finkelhor \& Browne, 1985). The effects of 
stigmatization include self-destructive behaviors like drug and alcohol abuse, criminal activity, prostitution, and even suicide. Psychologically, the guilt and shame broadcasted to the victims regarding their abuse can lead to low self-esteem and feelings of loneliness and rejection (Finkelhor \& Browne, 1985).

Stigmatization can manifest in many different forms of self-destructive behaviors. In a twin study, childhood sexual abuse was found to be significantly associated with substance use (Kendler et al., 2000). When controlling for family background and parent psychopathology, twins exposed to CSA were still significantly more likely to develop substance use disorder (Kendler et al., 2000). Additionally, consequences of stigmatization include criminal activity and prostitution. Children with a history of CSA are likely to be involved in the justice system in adolescence and adulthood (Widom, 1995). Children with a history of CSA are 4.7 times more likely than non-victims to be arrested for general sex crimes in adulthood. In particular, they are 27.7 times more likely to be arrested for prostitution and 7.6 times more likely to arrested for violent sex crimes like rape or sodomy than individuals without a history of CSA (Widom, 1995).

Although not one of the four traumagenic dynamics, childhood sexual abuse is also a significant predictor of revictimization later in life (Walker, Freud, Ellis, Fraine, \& Wilson, 2017). A meta-analysis of the prevalence of sexual revictimization among survivors of CSA found the average rate of revictimization to be almost $48 \%$ (Walker et al., 2017). Female victims of CSA are also twice as likely as non-abused women to be physically revictimized in adulthood (Barnes, Noll, Putnam, \& Trickett, 2009). Researchers have found that CSA is predictive of intimate partner violence in adult relationships, including forced sexual activity (Daigneault, Hebert, \& McDuff, 2009). For example, researchers have found that those with a history of CSA 
report 1.6 more physical altercations, including domestic violence, as their non-abused counterparts (Noll, Horowitz, Bonanno, Trickett, \& Putnam, 2003). Because revictimization may be related to one's ability to identify and react to risky situations, the next section will review the literature on risk recognition.

\section{Risk Recognition}

Risk recognition is a concept that refers to an individual's ability to recognize danger in given situations (Bockers, Roepke, Michael, Renneberg, \& Knaevesrud, 2014). Risk recognition can be measured in two ways - risk appraisal and risk response (VanZile-Tamsen, Testa, \& Livingston, 2005). Risk appraisal is an individual's ability to evaluate the danger in a situation through feelings of uncomfortableness and unpleasantness with the situation. Risk response is an individual's ability to act in a dangerous situation, like leaving the situation when they feel that it has escalated too far (VanZile-Tamsen et al., 2005).

Many different factors, including alcohol consumption, inhibit an individual's ability to recognize risk. Loiselle and Fuqua (2007) experimentally studied the effects of alcohol on women's ability to detect risk in date-rape scenarios using two groups: an alcohol consumption group and a control/placebo group. Researchers measured risk recognition using response latency, or the number of seconds until the participants said that the situation should end. Individuals in the placebo group averaged a response latency of 92.19 seconds, indicating that the man in the scenario should have stopped sexual advances after the woman first told him no (Loiselle \& Fuqua, 2007). Individuals in the alcohol group, with a blood alcohol concentration of $.04 \%$, had an average response latency of 134.38 seconds, indicating that the man should have stopped advances after the man touched the woman, the woman told him no, and the two got into 
an angry encounter (Loiselle \& Fuqua, 2007). These findings suggest that alcohol significantly impairs an individual's ability to recognize risk in dangerous situations.

Risk recognition also varies by the whether the perpetrator is a stranger or someone known to the individual. In an experimental study, researchers found that women were more likely to perceive risk in new social relationships (strangers) than among individuals with whom they have a history (acquaintance). Further research has found that an individual's risk recognition to an acquaintance situation is more predictive of revictimization than an individual's risk recognition among strangers (Gidycz et al., 2006).

Another factor that might significantly lower an individual's ability to recognize risk is a history of CSA. Researchers hypothesize that higher response latency (or lower risk recognition) might explain high rates of revictimization in this population. Victims of intimate partner violence have higher response latency when watching video vignettes of aggressive encounters than non-victims (Witte \& Kendra, 2010). Bockers et al. (2014) examined responses to danger cues among individual with a history of CSA and those with a history of CSA and subsequent revictimization. Those who had experienced CSA, but not revictimization, responded to danger cues more quickly than those who had been revictimized (Bockers et al., 2014). These results suggest that individuals may have a developed sensitivity to danger such that a history of CSA combined with repeated victimization is related to lower levels of risk recognition (or higher response latency). Walsh, DiLillo, and Messman-Moore (2012) found that a history of abuse was related to deficits in many domains of emotion regulation, poor coping strategies, and low impulse control. These deficits are then related to impaired ability to recognize risk, which in turn increases the likelihood of revictimization in this population (Walsh et al., 2012). 
Porter, Koch, Saules, and Sexton (2015) studied differences in risk recognition among individuals with and without a history of sexual assault using response latency. These researchers found no differences in risk response, but significant differences in perceptions of consequences of date-rape scenarios. For example, individuals with a history of sexual assault were more likely to perceive that the situation would end in consensual sex than those without a history of sexual assault (Porter et al., 2015). Researchers also found that individuals with a history of sexual assault were more likely to perceive that after she left the situation, the male might think negatively of the female and tell others about her leaving (Porter et al., 2015).

Soler-Baillo, Marx, and Sloan (2005) studied the physiological signs of risk recognition among both individuals with a history of adult sexual violence and non-victims listening to a recording of a hypothetical date rape scenario. Victims took significantly longer to recognize danger in the hypothetical situation than did non-victims. When examining physiological responses to the dangerous situation, victims displayed lower heart rate reactivity than nonvictims (Soler-Baillo et al., 2005). These results suggest that individuals with a history of sexual violence are less reactive, both cognitively and physiologically, to potentially dangerous situations.

Childhood sexual abuse and risk recognition are likely related to personality characteristics. As mentioned above childhood sexual abuse is related to many outcomes, including personality disorders (McLean \& Gallop, 2003). Risk recognition may also be related to personality characteristics. The next section will review the available literature on personality characteristics and connections to CSA as well as risk recognition. 


\section{Personality}

Personality is defined as the emotions, cognitions, and behaviors that make an individual unique (John, Robins, \& Pervin, 2008). The five-factor theory of personality is a trait theory, in which individuals have relatively consistent patterns of thoughts, feelings, and actions. Fivefactor theory is a personality system, which operates under the assumption that an individual's basic tendencies, characteristic adaptations, and self-concept interact with biological bases, external influences, and objective biography to determine how personality is expressed at any given time (John et al., 2008).

Costa and McCrae (1995) developed the Big Five model of personality, a lexical approach that filters a wide range of personality traits into five categories: extraversion, agreeableness, conscientiousness, neuroticism, and openness to experience. Extraversion is defined through facets such as gregariousness, assertiveness, activity, excitement-seeking, positive emotions, and warmth. Agreeableness is characterized by altruism, modesty, trust, tender-mindedness, compliance, and straightforwardness. Conscientiousness is defined through order, achievement, dutifulness, self-discipline, competence, and deliberation. Neuroticism is assessed by anxiety, angry hostility, depression, self-consciousness, vulnerability, and impulsiveness. Finally, openness is characterized through ideas, aesthetics, fantasy, actions, feelings, and values (John et al., 2008). Cross-cultural studies have found that these five characteristics, adapted to fit different cultures and languages, seem to universally representative personality characteristics (John et al., 2008).

Twin studies have been used to investigate the genetic and environmental influences of all five components of the five-factor model. Researchers have found that openness to experience, conscientiousness, extraversion, agreeableness, and neuroticism are substantially 
influenced by genetics (Loehlin, McCrae, Costa, \& John, 1998). Using functional brain imaging, researchers have also been able to link individual differences in extraversion and neuroticism scores to individual differences in brain activation while participants engage in cognitiveaffective tasks (Canli, 2004).

Extraversion is the personality dimension that includes traits such as sociability, activity, and experiencing positive emotions (Costa \& McCrae, 1992). Individuals scoring high on extraversion are more likely to be sociable, fun-loving, and affectionate, while individuals scoring low are more likely to be withdrawn, unexcitable, and reserved (Costa \& McCrae, 1986). Individuals who are highly extraverted are likely to spend more time with other people (Pavot, Diener, \& Fujita, 1990). Research suggests that individuals who spend more time in social situations report more positive affect, which helps to explain why researchers have consistently found that individuals who score high on extraversion report higher subjective well-being (Pavot et al., 1990). However, components of extraversion including sociability and affection might be related to higher response latency due to an individual's desire to spend time with and be affectionate toward other people.

Agreeableness is the personality dimension that represents interpersonal behavior on a continuum from compassion to antagonism (Costa, McCrae, \& Dye, 1991). Through the facets of trust, straightforwardness, altruism, compliance, modesty, and tender-mindedness, agreeableness encompasses the characteristics of interpersonal behavior that shape an individual's self-image and world-views (Costa et al, 1991). Researchers have studied the validity of agreeableness as a dimension of personality under the concern that self-reported levels of agreeableness might be biased by self-favoring biases (Graziano \& Tobin, 2002). 
Results have indicated that agreeableness is not distorted by social desirability, and it seems to be an important, independent measure of personality characteristics (Graziano \& Tobin, 2002).

Researchers have found that low levels of agreeableness, or lower desire to maintain interpersonal relationships, is predictive of higher levels of aggression among adolescents (Gleason, Jensen-Campbell, \& Richardson, 2004). Similarly, agreeableness is related to interpersonal conflict, with high levels of agreeableness predicting the use of constructive strategies for dealing with conflict, and lower levels of agreeableness predicting the use of destructive strategies (Jensen-Campbell \& Graziano, 2001). Agreeableness is also predictive of an individual's likelihood of deflecting or accepting blame in blameworthy situations such that individuals high in agreeableness are more likely to accept blame and individuals low in agreeableness are more likely to deflect blame (Meier \& Robinson, 2004). A history of CSA, combined with high levels of agreeableness and self-blame, might influence revictimization by lowering risk recognition and raising self-blame in these situations.

According to Costa, McCrae, and Dye (1991), conscientiousness is a factor that encompasses many characteristics, including achievement, commitment to work, willpower, and initiative (proactive) and responsibility and cautiousness (inhibitive). The facets of conscientiousness focus on an individual's commitment to social justice, sense of capability, organization, self-discipline, and drive to succeed (Roberts, Chernyshenko, Stark, \& Goldberg, 2005). Subsequently, individuals that are highly conscientious are often seen as capable, organized, achievement-oriented, and self-disciplined (Costa et al., 1991).

Researchers studying the influence of conscientiousness on health behaviors found that high conscientiousness increased perceived risk (Hampson, Andrews, Barckley, Lichtenstein, \& Lee, 2000). Highly conscientious individuals were more likely to identify risky situations as 
risky and implement risk reduction behaviors that affected both oneself and other individuals (Hampson et al., 2000). Consequently, research suggests that individuals who score higher in conscientiousness are more likely to live 2 to 3 years longer than those individuals that scored lower in conscientiousness (Terracciano, Lockenhoff, Zonderman, Ferrucci, \& Costa, 2008). High levels of conscientiousness, which includes cautiousness, may be related to lower response latency.

Costa and McCrae (1987) defined neuroticism as the dimension of personality that includes the tendency to experience negative emotionality and related traits, including fearfulness, low self-esteem, social anxiety, poor impulse control, irritability, and even helplessness. Neuroticism is also related to sensitivity to interpersonal stressors (Gunthert, Cohen, \& Armeli, 1999). Individuals scoring high in neuroticism are more likely to report interpersonal stressors as the most stressful part of their day, react more negatively to those stressful events, and use maladaptive coping strategies to deal with stress (Gunthert et al, 1999). Neuroticism is also a risk factor for the development of major depression, and individuals high in neuroticism are also more sensitive to the effects of adverse life experiences (Kendler, Kuhn, \& Prescott, 2004). Neuroticism is characterized by negative emotionality, and researchers investigating the comorbidity between mood and anxiety disorders have found that neuroticism might be the common characteristic that accounts for this comorbidity among diagnoses (Griffith et al., 2010). Research also suggests that high levels of neuroticism are a significant risk factor for the development of psychosis, likely because of the traits of helplessness and low self-esteem associated with the dimension (Krabbendam et al., 2002).

In the Big Five theory of personality, openness to experience encompasses the areas in which an individual is open or closed, including fantasy, aesthetics, feelings, actions, ideas, and 
values (McCrae, 1993). The dimension of openness is the most broadly defined of the five factors. Researchers have found that intellect, a construct related to the area of ideas, is independently associated with general intelligence, verbal intelligence, and nonverbal intelligence (DeYoung, Quilty, Peterson, \& Gray, 2013). Openness has been found to be independently associated with verbal intelligence, suggesting that different areas of a single BigFive characteristic can be predictive of different outcomes (DeYong et al., 2013).

While developing the Diagnostic and Statistical Manual of Mental Disorders $-5^{\text {th }}$ Edition (DSM-5; American Psychiatric Association [APA], 2013), psychologists decided that clinicians should incorporate important personality characteristics into their assessments and set out to create a trait model of personality that included clinically relevant, maladaptive personality facets and domains (Krueger, Derringer, Markon, Watson, \& Skodol, 2012). Researchers developed 25 personality traits that make up five domains of maladaptive personality: negative affect, detachment, antagonism, disinhibition, and psychoticism. (Krueger et al., 2012). According to the DSM-5, while this trait model emphasizes maladaptive personality characteristics associated with mental disorders, the polar opposite of each domain and facet represents healthy and adaptive personality characteristics that can promote resilience (American Psychiatric Association, 2013).

Developers of the DSM-5 maladaptive personality model created this model to closely align with the five-factor model of personality (Gore \& Widiger, 2013). They hypothesized that the polar opposites of their maladaptive personality domains would be similar to the Big Five theory of personality but be more clinically relevant to practice. Factor analyses have found that these two measures do closely align, with negative affectivity related to neuroticism, detachment 
with extraversion, antagonism with agreeableness, disinhibition with conscientiousness, and psychoticism with openness (Gore \& Widiger, 2013).

The first domain, negative affectivity, the opposite of emotional stability and closely related to neuroticism, is defined as the frequent and intense experiencing of negative emotions and behavioral manifestations (APA, 2013). Negative affectivity includes the facets of emotional lability, anxiousness, separation insecurity, submissiveness, hostility, perseveration, depressivity, suspiciousness, and lack of restricted affectivity (APA, 2013). Detachment, the opposite of extraversion, is the avoidance of socioemotional experiences, including casual relationships, friendships, and intimacy. Characteristics of detachment include withdrawal, intimacy avoidance, anhedonia, depressivity, restricted affectivity, and suspiciousness. Antagonism, the opposite of agreeableness, is seen as an exaggerated sense of self-importance, antipathy toward others, and the using of others for self-fulfillment that puts people at odds with others (APA, 2013). Antagonism includes the facets of manipulativeness, deceitfulness, grandiosity, attention seeking, callousness, and hostility (APA, 2013). Disinhibition, the opposite of conscientiousness, is defined as impulsivity, lack of planning and consideration, and an orientation toward immediate gratification. Characteristics of disinhibition include irresponsibility, impulsivity, distractibility, risk taking, and lack of rigid perfectionism. Finally, psychoticism, the opposite of lucidity and closely related to openness, is defined as odd, eccentric, and having unusual thoughts and behaviors (APA, 2013). Psychoticism includes unusual beliefs and experiences, eccentricity, and cognitive and perceptual dysregulation (APA, 2013). Personality characteristics, both Big-5 personality and DSM-5 personality, are both influenced by and predictive of many negative outcomes. 
Whether using the Big Five or the DSM-5 maladaptive personality model, personality extremes can predict behavior issues and adjustment problems (Van den Akker et al., 2013). Children who initially measured in extremes on personality measures were more likely to develop internalizing and externalizing problems later in adolescence. Personality extremities were also predictive of childhood adjustment problems (Van den Akker et al., 2013).

A history of CSA has been found to be significantly related to impulsive personality characteristics in adolescence and adulthood (Harden, Carlson, Kretsch, Corbin, \& Fromme, 2015). In a sample of 2,245 undergraduate students, researchers measured the traits of sensationseeking (a characteristic of extraversion) and premeditation (a characteristic of conscientiousness). Results indicated that a history of CSA is related to higher levels of sensation seeking and lower levels of premeditation (Harden et al., 2015). Allen and Lauterbach (2007) found that survivors of both single-incident and prolonged CSA score higher on levels of neuroticism and openness to experience as adults than individuals with no childhood exposure to trauma. In yet another study, researchers found that a history of CSA was associated with lower levels of agreeableness (Moran et al., 2011). In short, research has found a connection between a history of CSA and personality characteristics, specifically higher extraversion, neuroticism and openness to experience and lower agreeableness and conscientiousness. In addition, personality characteristics may influence risk recognition. The proposed study will examine the relationship between CSA, personality characteristics, and risk recognition.

\section{The Current Study}

While there is an abundance of research on childhood sexual abuse, personality, and risk recognition as independent topics, there is a gap in the literature regarding the inter-relationships among these variables. The purpose of this study was to address this gap by examining the 
relationships between CSA, personality, and risk recognition. Understanding this relationship can help inform treatment decisions among survivors of CSA, help lower response latency, and provide a basis for reducing revictimization among this population.

The current study sought to replicate previous research suggesting that a history of CSA is related to higher levels of negative affectivity, psychoticism, disinhibition, and antagonism and lower levels of detachment, based upon research related to Big Five personality characteristics (Allen \& Lauterbach, 2007) as well as higher response latency (Bockers et al., 2014). The proposed study extended previous research by examining the relationship between personality characteristics and risk recognition among college-aged women. College-aged women, typically between the ages of 18 and 22 are in a distinct stage of life called emerging adulthood, in which individuals are exploring different identities in love, work, and worldviews (Arnett, 2000). Because emerging adulthood is such a pivotal time for relational development, and because women are more likely to experience CSA than men, the target population for the proposed study was college-aged women.

Research suggests that individuals with a history of CSA are likely to have lower risk recognition (higher response latency) in adulthood (Walsh, DiLillo, \& Messman-Moore, 2012). Based upon these findings, I developed the following hypothesis regarding the relationship between CSA and risk recognition:

H1: Individuals with a history of CSA would have higher response latency than individuals without a history of CSA.

Previous research suggests that a history of childhood sexual abuse is related to higher levels of extraversion, neuroticism, and openness to experience (Harden et al., 2015; Allen \& Lauterbach, 2007). Harden and colleagues (2015) also found that a history of CSA is related to 
lower levels of conscientiousness. Similarly, Finkelhor and Browne's (1985) traumagenic dynamics of traumatic sexualization, betrayal, stigmatization, and powerlessness are rooted psychological disturbances related to the facets of DSM-5 maladaptive personality characteristics. Based on these findings, I developed the following hypotheses regarding the relationship between CSA and personality:

H2: A history of CSA would be related to personality characteristics.

H2A: Women with a history of CSA would have higher levels of negative affectivity, psychoticism, disinhibition, and antagonism as well as lower levels of detachment than non-abused peers.

H2B: Women with a history of CSA would have higher levels of neuroticism, extraversion, and openness to experience as well as lower levels of conscientiousness and agreeableness than non-abused peers.

There is little research regarding the relationship between personality characteristics and levels of risk recognition; however, given facets like emotional lability, anxiousness, depressivity, suspiciousness, attention seeking, impulsivity, risk taking, and cognitive and perceptual dysregulation, it was expected that personality would be related to risk recognition. Similarly, given the previous research suggesting that a history of childhood sexual abuse is related to certain personality characteristics, and my hypotheses that personality characteristics would also be related to levels of risk recognition, I developed the following hypotheses:

H3: Personality characteristics would be related to risk recognition.

H3A: Negative affectivity, detachment, disinhibition, and psychoticism would be related to worse risk recognition (longer response latency) and antagonism would be related to better risk recognition (shorter response latency). 
H3B: Neuroticism, extraversion, agreeableness, and openness to experience would be related to worse risk recognition (longer response latency) and conscientiousness will be related to better risk recognition (shorter response latency).

Despite research that states that there is a relationship between childhood sexual abuse and risk recognition, childhood sexual abuse and personality characteristics, and personality characteristics and risk recognition, there is a gap in the research regarding the interrelationship between these variables. In response to this gap in the literature, I developed the following research question:

Research Question \#1: What is the relationship between childhood sexual abuse, personality characteristics, and risk recognition? 


\section{CHAPTER III: RESEARCH METHODOLOGY}

\section{Participants}

This study included 223 female undergraduate students from Illinois State University. Women ranged in age from 18 to 25 , with a mean age of 19.16 years $(S D=1.35)$. Of the 223 female undergraduate participants, 139 participants (62.3\%) were in the non-CSA group, and 84 participants (37.7\%) were in the CSA group. Based upon participant self-reports, 150 (67.3\%) identified as Caucasian, 30 (13.5\%) identified as African-American, 29 (13.0\%) identified as Hispanic/Latino, 7 (3.1\%) identified as Asian-American, and 7 (3.1\%) identified as mixed ethnicity. Most participants (89.2\%) identified as heterosexual, while $3.1 \%$ identified as homosexual, $6.3 \%$ identified as bisexual, $0.9 \%$ identified as pansexual, and $0.4 \%$ identified as other. Among participants in this study, 55.6\% reported being single, 39.9\% reported dating someone, $3.6 \%$ reported living with a significant other, and $0.9 \%$ reported other.

Based on participant self-reports, 141 participants (63.1\%) reported coming from intact families in which their parents were currently married, 49 participants (22\%) reported parents being divorced, 29 participants (13\%) reported a single-parent household, and 3 participants (1.3\%) reported other; 1 participant did not answer. Participants also self-reported parents' highest level of education. Seven participants (3.1\%) reported that their mother or stepmother attended high school but did not receive a degree, 59 (26.5\%) completed a high school degree, $39(17.5 \%)$ completed 2 years of college, 74 (33.2\%) completed a bachelor's degree, and 44 $(19.7 \%)$ completed a graduate degree. Among fathers and stepfathers, $19(8.5 \%)$ attended some high school, 63 (28.3\%) completed high school, 34 (15.2\%) completed 2 years of college, 73 (32.7\%) completed a bachelor's degree, and $33(14.8 \%)$ completed a graduate degree; 1 participant did not answer. 


\section{Instruments}

\section{Demographic Questionnaire}

Participants were asked to complete a demographics questionnaire to gather information on age, gender, sexual orientation, ethnicity, family income, and family composition.

\section{Childhood Sexual Abuse}

CSA was assessed using the Hot Topics Questionnaire. The Hot Topics Questionnaire, developed by Reese-Weber and Smith (2011), is a 15-item questionnaire with five questions each about mental health, substance abuse, and childhood sexual abuse. The questions targeting childhood sexual abuse on the Hot Topics Questionnaire are:

“1) Before the age of 18 , someone has sexually touched me in ways that made me feel uncomfortable; 2) Before the age of 18 , I had a sexual experience with an individual five or more years older than myself (any sexual activity involving physical contact); 3)

Before the age of 18 , another person has coerced me to engage in sexual activity (intercourse, oral sex, anal sex, petting/fondling); 4) Before the age of 18, I engaged in sexual activity (intercourse, oral/anal sex, petting) when I didn't want to because someone threatened to use physical force; 5) Before the age of 18, I have been sexually assaulted."

Response choices are yes or no. Participants who answered yes to any of the five questions were placed into the CSA group and were administered a follow-up questionnaire. Individuals that responded no to all five of the questions were placed into the non-CSA group. Individuals who answered yes to any of the CSA questions on the Hot Topics Questionnaire were then administered the Child Sexual Abuse Questionnaire (CASQ; Finkelhor, 1979). The CASQ asks 10 questions about an individual's sexual experiences prior to the age of 
16. Specifically, this measure gathers information on the age at time of abuse, age of the perpetrator, relationship to the perpetrator, type of abuse, use of force, number of instances, length of abuse, and disclosure of abuse. Risin and Koss (1988) have found that the CASQ has good internal validity.

\section{Personality}

Participants completed the Personality Inventory for DSM-5 - Brief Form (PID-5-BF; Krueger, Derringer, Markon, Watson, \& Skodol, 2013) to assess personality characteristics. The PID-5-BF is a 25-item questionnaire that measures maladaptive personality traits related to the DSM-5, including negative affect, detachment, antagonism, disinhibition, and psychoticism. Individuals rated how well each statement relates to their personality on a 4-point Likert scale, with 0 being Very False or Often False and 3 being Very True or Often True. Researchers conducting factor analyses have found that the PID-5-BF does indeed measure five traits of

personality (Fossati, Krueger, Markon, Borroni, \& Maffei, 2013). Krueger and colleagues (2013) found good internal consistency in a representative sample for negative affect (.93), detachment (.96), antagonism (.95), disinhibition (.84), and psychoticism (.96). In the present study, alpha coefficients were .77 for negative affect, .73 for detachment, .71 for antagonism, .77 for disinhibition, and .80 for psychoticism.

Participants also completed the Big Five Inventory (BFI; John \& Srivastava, 1999) to assess personality characteristics. The BFI is a 44-item questionnaire that measures the Big Five personality characteristics of extraversion, agreeableness, conscientiousness, neuroticism, and openness to experience. Individuals rated how well each statement relates to their personality on a 5-point Likert scale, with 1 being strongly disagree and 5 being agree strongly. Researchers have found BFI scores to have internal consistency ranging from .79 to .87 , thus suggesting that 
the BFI is a reliable short-form measure of the Big Five personality traits (John, Robbins, \& Pervin, 2008). In the present study, alpha coefficients were .87 for extraversion, .77 for agreeableness, .80 for conscientiousness, .83 for neuroticism, and .73 for openness to experience.

\section{Risk Recognition}

Risk recognition, including risk appraisal and risk response, was measured by response latency using a date-rape vignette. Marx and Gross (1995) developed an audio vignette depicting a date-rape situation and asked participants to indicate when they thought the man had become sexually violent. Response latency is measured by the duration of the audio prior to indicating the situation had become violent. Abbey, Buck, Zawiacki, and Saenz (2003) developed a similar vignette in which a couple is drinking together at a party, the woman denies sex, and the man exerts verbal pressure toward the woman. In the present study, these previously developed vignettes served as the basis for modified vignette used to measure risk recognition. In the modified vignette, two individuals connect on a dating app, chat, and eventually meet in person. The man in the vignette eventually becomes physically and verbally aggressive. The vignette was divided into 13 scenes. At the end of each scene, participants were asked to answer two questions: "Would you be comfortable in this situation?" (risk appraisal) and "Would you continue this interaction?" (risk response). Response choices were yes, maybe, and no. Risk appraisal was measured by the scene number in which a participant answered no to the first question. Risk response was measured by the scene number in which a participant answered no to the second question. Risk recognition was measured by the scene number in which participants answered no to both questions. Shorter response latency scores indicated better risk recognition whereas longer response latency scores indicated worse risk recognition. 


\section{Procedure}

Participants were recruited using the psychology department's online recruiting system, SONA. When participants arrived at the study, researchers greeted participants and welcomed them to an online dating study. Researchers showed participants the Hot Topics Questionnaire to provide a sample of the questions that participants were going to be asked to answer. Participants then read and signed an informed consent, and then they began a computer administered survey. Participants were asked to complete the survey including the demographics questionnaire, the Hot Topics Questionnaire, a follow-up CASQ for the CSA group, the BFI, and the PID-5-BF.

Upon completion of the surveys, participants were instructed to choose five individuals that they would be hypothetically interested in talking with and then asked to complete a short biography for an online dating profile. After completing the online dating portion of the survey, participants were randomly assigned to either a rejection or non-rejection condition and given either two matches (rejection) or eight matches (non-rejection). Data based on the rejection manipulation was not used in the current study.

Participants were then asked to read through a scenario of two people meeting online. After each section of the scenario, participants were asked to respond to a question on risk appraisal and a question on risk response. When participants answered no to both the risk appraisal question and the risk response question, the vignette ended. Following the completion

of the study, participants were debriefed on the true purpose of the study, were given a debriefing statement, and received contact information for resources for survivors of childhood sexual abuse and adult sexual assault. 


\section{CHAPTER IV: RESULTS}

The first hypothesis, that individuals with a history of CSA would have higher response latency than individuals without a history of CSA, was analyzed using an independent samples $t$ test. Analyses indicate that participants who experienced CSA $(M=3.39, S D=1.35)$ did not demonstrate significantly higher response latency (when participant said no to both questions) than those in the non-CSA group $(M=3.49, S D=1.77), t(221)=0.43, p=.367$.

In the current study, personality was assessed using two different measures: the Big Five Inventory (BFI) and PID-5-BF. These measures assess Big Five personality characteristics and related DSM-5 personality characteristics. Correlations between the two measures are presented in Table 1. Results of this analysis indicate significant correlations across measures, excluding psychoticism and openness to experience. In addition, each of these significant correlations were found to be in the hypothesized direction. These correlations provide insight when interpreting results of the analyses of the relationship between personality and risk recognition. 
Table 1.

Bivariate Correlations Across Big Five and DSM-5 Personality Characteristics

\begin{tabular}{cccccc}
\hline Personality & Detachment & Antagonism & Disinhibition & Negative & Psychoticism \\
& & & & Affectivity \\
Extraversion & $-.47^{* *}$ & -.06 & .06 & $-.32^{* *}$ & $-.26^{* *}$ \\
Agreeableness & $-.46^{* *}$ & $-.51^{* *}$ & $-.30^{* *}$ & $-.33^{* *}$ & $-.36^{* *}$ \\
Conscientiousness & $-.31^{* *}$ & $-.34^{* *}$ & $-.60^{* *}$ & $-.38^{* *}$ & $-.41^{* *}$ \\
Neuroticism & $.37 * *$ & $.21 * *$ & $.17 *$ & $.69 * *$ & $.32 * *$ \\
Openness & -.10 & -.07 & -.01 & -.09 & -.01 \\
\hline
\end{tabular}

Note. $* \mathrm{p}<.05, * * \mathrm{p}<.01$

The second hypothesis (part A), that women with a history of CSA would have higher levels of negative affectivity, psychoticism, and disinhibition as well as lower levels of detachment and antagonism than non-abused peers, was examined using five independent samples $t$-tests. Results of the independent samples $t$-tests can be found in Table 2. Hypothesis 2A was partially supported in that history of CSA was associated with higher levels of negative affectivity, psychoticism, and disinhibition. Participants with a history of CSA did not show significantly lower levels of detachment or antagonism; instead, participants in the CSA group showed significantly higher levels of detachment and antagonism than non-abused peers. 
Table 2.

T-statistics, Means, and Standard Deviations for Personality Characteristics in CSA and Non-CSA Groups

\begin{tabular}{|c|c|c|c|c|c|}
\hline \multirow[t]{2}{*}{ Group Membership } & \multicolumn{2}{|c|}{ Child Sexual Abuse } & \multicolumn{2}{|c|}{ Non-CSA Group } & \multirow[t]{2}{*}{$t$-statistic } \\
\hline & $M$ & $S D$ & $M$ & $S D$ & \\
\hline Negative Affectivity & 12.65 & 2.99 & 11.53 & 3.56 & $t(198.27)=-2.54, p=.012$ \\
\hline Detachment & 8.67 & 3.02 & 7.70 & 2.55 & $t(153.12)=-2.46, p=.015$ \\
\hline Antagonism & 7.61 & 2.38 & 6.84 & 2.15 & $t(221)=-2.49, p=.013$ \\
\hline Disinhibition & 8.49 & 2.87 & 7.66 & 2.85 & $t(221)=-2.09, p=.038$ \\
\hline Psychoticism & 9.08 & 3.20 & 8.17 & 3.17 & $t(221)=-2.09, p=.038$ \\
\hline Extraversion & 26.59 & 7.36 & 27.29 & 6.60 & $t(221)=0.74, p=.463$ \\
\hline Agreeableness & 35.83 & 5.79 & 37.57 & 5.79 & $t(221)=2.34, p=.020$ \\
\hline Conscientiousness & 33.41 & 5.40 & 33.36 & 6.20 & $t(221)=-0.06, p=.949$ \\
\hline Neuroticism & 28.26 & 5.92 & 25.84 & 6.73 & $t(221)=-2.72, p=.007$ \\
\hline Openness to Experience & 34.99 & 5.93 & 33.83 & 5.96 & $t(221)=-1.41, p=.159$ \\
\hline
\end{tabular}


The second hypothesis (part B), that women with a history of CSA would have higher levels of neuroticism, extraversion, and openness to experience as well as lower levels of conscientiousness and agreeableness than non-abused peers, was examined using independent samples $t$-tests. Results of the independent samples $t$-tests can be found in Table 2. Hypothesis 2B was partially supported in that participants with a history of CSA demonstrated higher levels of neuroticism and lower levels of agreeableness than non-abused peers. The hypothesis was not supported for extraversion, conscientiousness, and openness to experience.

The third hypothesis (part A), that negative affectivity, detachment, disinhibition, and psychoticism will be related to longer response latency and that antagonism would be related to shorter response latency, was analyzed using a regression analysis. Results of the regression are shown in Table 3, Model 1. Hypothesis 3A was not supported, with only psychoticism significantly related to response latency (risk recognition) such that participants who reported more psychotic characteristics had longer response latency scores (worse risk recognition). The multiple regression model indicates that DSM-5 personality characteristics predict approximately $3 \%$ of the variance in risk recognition, $F(5,217)=1.22, p=.30$. To partially answer the research question about the relationship between childhood sexual abuse, personality characteristics, and risk recognition, a regression analysis was conducted to determine the relationship between each of the DSM-5 personality characteristics and risk recognition, while controlling for all other variables. Adding CSA as a predictor did not increase $R^{2}, \Delta R^{2}=.001, F(1,216)=0.29, p=.59$ (see Table 3, Model 2). 
Table 3 .

Relationship between Risk Recognition, Negative Affectivity, Detachment, Antagonism, Disinhibition, and Psychoticism

Dependent Variable: Risk Recognition

\begin{tabular}{|c|c|c|c|c|}
\hline Model & & $B$ & $S E B$ & $\beta$ \\
\hline \multirow[t]{5}{*}{1} & Negative Affectivity & -.06 & .04 & -.12 \\
\hline & Detachment & -.02 & .05 & -.03 \\
\hline & Antagonism & .03 & .06 & .04 \\
\hline & Disinhibition & -.01 & .05 & -.03 \\
\hline & Psychoticism & $.10^{*}$ & .05 & .20 \\
\hline Model & & $B$ & $S E B$ & $\beta$ \\
\hline \multirow[t]{6}{*}{2} & Negative Affectivity & -.06 & .04 & -.12 \\
\hline & Detachment & -.01 & .05 & -.02 \\
\hline & Antagonism & .03 & .06 & .05 \\
\hline & Disinhibition & -.01 & .05 & -.02 \\
\hline & Psychoticism & $.10^{*}$ & .05 & .20 \\
\hline & CSA & -.12 & .23 & -.04 \\
\hline
\end{tabular}

The third hypothesis (part B), that neuroticism, extraversion, agreeableness, and openness to experience would be related to longer response latency and that conscientiousness would be related to shorter response latency, was analyzed using regression analysis. Results of the regression analysis are shown in Table 4, Model 1. Hypothesis 3B was not supported. Neuroticism was found to be significantly negatively associated with response latency (risk 
recognition). In other words, participants who reported more neurotic personality characteristics had shorter response latency scores (better risk recognition). The multiple regression model indicates that Big 5 personality characteristics predict approximately $5 \%$ of the variance in risk recognition, $F(5,217)=2.43, p=.04$. To partially answer the research question about the relationship between childhood sexual abuse, personality characteristics, and risk recognition, a regression analysis was conducted to determine the relationship between CSA and risk recognition while controlling for each of the Big 5 personality characteristics. Adding CSA as a predictor did not increase $R^{2}, \Delta R^{2}=.00, F(1,216)=0.53, p=.83$. 
Table 4.

Relationship between Risk Recognition, Extraversion, Agreeableness, Conscientiousness, Neuroticism, Openness to Experience, and CSA

Dependent Variable: Risk Recognition

\begin{tabular}{|c|c|c|c|c|}
\hline Model & & $B$ & $S E B$ & $\beta$ \\
\hline \multirow[t]{5}{*}{1} & Extraversion & -.02 & .02 & -.10 \\
\hline & Agreeableness & -.04 & .02 & -.14 \\
\hline & Conscientiousness & -.02 & .02 & -.08 \\
\hline & Neuroticism & $-.06 *$ & .02 & -.23 \\
\hline & Openness to Experience & .00 & .02 & .01 \\
\hline Model & & $B$ & $S E B$ & $\beta$ \\
\hline \multirow[t]{6}{*}{2} & Extraversion & -.02 & .02 & -.10 \\
\hline & Agreeableness & -.04 & .02 & -.14 \\
\hline & Conscientiousness & -.02 & .02 & -.08 \\
\hline & Neuroticism & $-.06 *$ & .02 & -.23 \\
\hline & Openness to Experience & .00 & .02 & .01 \\
\hline & CSA & -.05 & .23 & -.02 \\
\hline
\end{tabular}




\section{CHAPTER V: DISCUSSION}

Researchers have found that childhood sexual abuse is an incredibly common issue, with approximately 20-30\% of women in the United States having reported a history of CSA (Dube et al., 2005). Results of the current study demonstrate that prevalence rates may be even higher than previous estimates, with nearly $40 \%$ of participants reporting a history of CSA. Previous research also suggests that a history of CSA is related to higher response latency (and potentially, subsequent revictimization) and different personality characteristics (Walsh, DiLillo, \& Messman-Moore, 2012; Harden et al., 2015; Allen \& Lauterbach, 2007).). The results suggested that a history of CSA was related to higher levels of negative affectivity, psychoticism, disinhibition, and neuroticism, as well as lower levels of agreeableness. Results also showed that neuroticism was found to be significantly negatively correlated to response latency and psychoticism was significantly positively correlated to response latency. The results did not show a significant relationship between a history of CSA and levels of response latency.

Previous research has been mixed regarding the connection between a history of CSA and risk recognition. For example, in one study, individuals with a history of CSA were found to have higher response latency in adulthood, subsequently leading to revictimization (Walsh, DiLillo, \& Messman-Moore, 2012). Witte and Kendra (2010) found that victims of intimate partner violence demonstrated significantly higher response latency; similarly, Walsh, DiLillo, and Messman-Moore (2012) found that a history of abuse was correlated to deficits in domains related to risk recognition. However, other researchers studying risk recognition among victims and non-victims have found no differences in response recognition (Porter, Koch, Saules, \& Sexton, 2015). Results of the current study suggest similar levels of risk recognition among CSA and non-CSA groups. Differences in results among the current study and previous research could 
be due to differences in methodology, as each study measures risk recognition differently using different vignettes to demonstrate risk.

Based upon previous research, we expected about $25 \%$ of our study population to report a history of CSA; instead, almost 40\% of our participants reported a history of CSA. This stark difference in the prevalence of CSA could be attributed to the momentum of the \#MeToo movement and the attention this has brought to these experiences. In October 2017, the New York Times reported that Harvey Weinstein had a history of using his prominence to sexually assault and sexually harass women throughout Hollywood (Tippett, 2018). In response to this story, Alyssa Milano asked twitter followers to share their own history of sexual harassment or sexual assault with the hashtag \#MeToo. Since then, this movement has garnered substantial momentum. While many high-profile actors, producers, comedians, and politicians have been held accountable for their actions of sexual violence, women all over the country have also used this movement to come forward with their own stories of abuse and to stand in solidarity with others (Tippett, 2018). For those individuals that have not felt comfortable disclosing their experiences to the public, the movement has certainly brought an awareness to the commonality of sexual harassment and sexual abuse (Tippet, 2018). The unexpectedly high rate of rate of participants who reported a history of CSA in the current study as compared to previous studies may be due in part to increased awareness and willingness to report such abuse among this generation.

Similarly, it is possible that the \#MeToo movement had an influence on risk recognition. Specifically, it is possible that with increased attention on sexual violence in many different aspects of life, college-aged women have become more aware of the dangers associated with this phase of life and the environment in which they are in. By spreading awareness of the 
commonality of sexual assault, the \#MeToo movement might attribute to increased levels of risk recognition (lower response latency) among all groups within the current study.

In the current study, personality characteristics were assessed using two different measures that use a five factor model (John et al., 2008). One measure, the Big 5, uses labels consistent with the theory. The second measure, the PID-5, was developed to align with Big Five personality but to be more focused on clinical aspects of personality. Hence, labels for the five factors are different from those of the Big 5. In the current study, negative affectivity and neuroticism are similar concepts across measures. Results of the current study found that a history of CSA was significantly related to higher levels of negative affectivity and higher levels of neuroticism. These results are consistent with previous findings, in which survivors of CSA scored significantly higher on measures of neuroticism (Allen \& Lauterbach, 2007).

Psychoticism is the DSM-5 personality characteristic closely related to the Big-5 characteristic of openness to experience, though in the current study no significant correlation between these two characteristics was found. In the current study, a history of CSA was found to be significantly related to higher levels of psychoticism. These findings are also consistent with previous research in which a history of CSA was related to higher levels of openness to experience, as measured by the Big 5 (Allen \& Lauterbach, 2007). The current study did not replicate previous Big-5 research in which a history of CSA would be related to higher levels of openness (Allen \& Lauterbach, 2007). Instead, no significant relationship between openness to experience and a history of CSA was found. As will be discussed later, differences in these findings may be attributed to differences in measures and the convenience sample used in the study. 
Disinhibition is the DSM-5 characteristic associated with conscientiousness on the Big-5 measure. In the current study, a history of CSA was found to be significantly related to higher levels of disinhibition but not significantly related to conscientiousness. Findings related to a history of CSA and disinhibition are consistent with previous research, though the current study did not replicate previous findings in which a history of CSA is related to a lower levels of conscientiousness (Harden et al., 2015). Instead, no significant relationship was found.

Detachment is the DSM-5 characteristics related to extraversion, as measured by the Big5 measure. Contrary to previous research and to my hypothesis, the current study found that a history of CSA was related to higher levels of detachment but found no relationship between a history of CSA and extraversion. These findings are inconsistent with previous research in which a history of CSA was related to higher levels of extraversion (Harden et al., 2015). Given that detachment is the opposite of extraversion, the findings of this study were unexpected. Considering these results through the lens of Finkelhor and Brown's (1985) theoretical framework helps to understand these results. The dynamics of traumatic sexualization, betrayal, powerlessness, and stigmatization are feature different characteristics also related to detachment. These dynamics likely attribute to the positive correlation between CSA and detachment. Further investigation regarding the relationship between these characteristics and the applications to the general population are necessary to better understand the inconsistencies in findings.

Finally, antagonism is the DSM-5 personality characteristic associated with agreeableness, as measured by the Big-5. In the current study, a history of CSA was related to higher levels of antagonism and lower levels of agreeableness. These findings are consistent with previous research, in which a history of CSA was related to lower levels of agreeableness (Moran et al., 2011). Following Finkelhor and Brown's (1985) framework, a history of CSA is 
likely related to lower levels of agreeableness due to the betrayal and stigmatization that occur due to abuse and the loss of trust and modesty associated with these dynamics. These results are vital in better understanding potential reasons for lower levels of risk recognition (or higher response latency) among individuals with a history of CSA.

As stated above, one reason that the current findings related to the Big-5 personality characteristics were inconsistent with previous research may be due to differences in samples, as college students represent more of a community sample while previous research has involved clinical samples. In addition, the current study demonstrated more significant relationships between CSA and DSM-5 maladaptive personality traits than CSA and Big-5 personality. These differences can be attributed to the fact that the DSM-5 personality characteristics were developed to provide a more practical, clinical measure for personality. Since these measures were developed to be more useful to clinicians working with clients, it is possible that these measures were more applicable and relatable to the study population at hand.

Based on previous research, in the current study I hypothesized that negative affectivity, detachment, disinhibition, and psychoticism would be related to higher response latency and that antagonism would be related to lower response latency. Rather, only psychoticism was found to be related to response latency in the predicted direction. Similarly, it was hypothesized that neuroticism, extraversion, agreeableness, and openness to experience would be related to higher response latency and that conscientiousness would be related to lower response latency. In the model analyzing the relationship between Big Five personality and risk recognition, only neuroticism was significantly related to response latency. While one personality characteristic in each model was significantly related to risk recognition as predicted, these findings alone are not enough to support a conclusion that personality factors are indeed predictive of levels of risk 
recognition. These findings are inconsistent with previous research, which suggests that certain personality characteristics and deficits in domains of emotion regulation, coping skills, and impulse control are related to significantly lower levels of risk recognition (Walsh, DiLillo, \& Messman-Moore, 2012). Inconsistencies in these findings may be attributed to the non-clinical nature of the study population. Future research investigating the relationship between personality and risk recognition in clinical samples might find results that are consistent with previous literature.

\section{Limitations and Future Directions}

As with all studies, there are limitations within the current study. One limitation is the use of a convenience sample of female college students. Typically, students who are successful enough to attend a 4-year university are relatively well-adjusted. Big-5 personality measures have been developed to provide insight into personality profiles and extremes while DSM-5 personality measures provide information about characteristics related to mental disorders and maladaptive personality traits. Among a community sample - especially among college students - it's unlikely to see a significant personality extremes. It is possible that the "normalness" of the personalities of the study population led to inconsistent findings related to the relationship between CSA, personality, and risk recognition. Still, the use of two personality measures (including the PID-5, assessing DSM-5 maladaptive personality and developed to be more clinically applicable) helps to address the effects of this limitation. Conducting this research in a true community sample, representative of individuals with many different backgrounds, might allow for better insight into the significance of the relationship between personality and other variables. 
Due to this research being conducted in conjunction with another research project, part of the study procedure included deception and a rejection manipulation. While the effects of the rejection manipulation were not analyzed in this study, it is possible that feelings of rejection contributed to response latency for individuals in both the rejection and non-rejection groups. The study was designed to minimize this influence, with the rejection manipulation occurring at the conclusion of the computer-administered survey, but participants were not asked to complete the risk recognition vignette until after the rejection manipulation. Results of this study should be interpreted with this in mind.

Another limitation of the current study was the use of an original vignette created specifically for this study. While this vignette was adapted from those used in previous research, it is still an entirely new measure without any research regarding validity. Further investigation into the validity of this vignette in providing a scenario to measure risk recognition is necessary in order to better understand the significance of this limitation.

\section{Strengths and Conclusions}

One strength of the current study was the investigation of the relationship between the three study variables - CSA, personality, and risk recognition. Previous research has analyzed the relationships between CSA and risk recognition, CSA and personality, and personality and risk recognition, but researchers have yet to analyze the relationship between the three variables. The present study examined the relationships between CSA, personality, and risk recognition through the use of two personality measures and an adapted risk recognition vignette. Understanding these relationships can provide more information on the different factors that lead to lower levels of risk recognition and, potentially, subsequent revictimization in adulthood. While results related to the hierarchical regression and the fit of the model in predicting risk recognition were 
insignificant, this study paves the way for future research to consider each of these variables in relation to each other in predicting risk recognition and possible revictimization.

Results of the current study also provide insight into the different personality factors that significantly lower an individual's ability to recognize risk. Awareness of these characteristics is the first step in reducing revictimization. For example, understanding the unique personality characteristics an individual possesses that might lead to lower risk recognition (or higher response latency) provides clinicians with the knowledge and ability to develop specific interventions targeting these deficits in order to decrease an individual's likelihood of revictimization. In the current sample, the characteristics of psychoticism and neuroticism were found to be significantly related to risk recognition, even when controlling for CSA. These findings provide evidence of the importance of some personality characteristics in predicting an individual's ability to recognize risk, even without a history of CSA. If well-adjusted, collegeaged individuals with and without a history of CSA are susceptible to deficits in risk recognition based on their personality characteristics, it can be hypothesized that individuals in a true community sample, with a history of trauma, are at even more risk for these deficits in risk recognition. Further research regarding the influence of trauma and personality characteristics in predicting risk recognition is needed to provide insight into factors that substantially reduce risk recognition. 


\section{REFERENCES}

Allen, B., \& Lauterbach, D. (2007). Personality characteristics of adult survivors of childhood trauma. Journal of Traumatic Stress, 20, 587-595. doi: 10.1002/jts.20195

American Psychiatric Association. (2013). Diagnostic and statistical manual of mental disorders (5th ed.). Washington, DC: Author.

Arnett, J. J. (2000). Emerging adulthood: A theory of development from the late teens through the twenties. American Psychologist, 55, 469-480. doi: 10.1037/0003-066X.55.5.469

Barnes J. E., Noll, J. G., Putnam, F. W., \& Trickett, P. K. (2009). Sexual and physical revictimization among victims of severe childhood sexual abuse. Child Abuse \& Neglect, 33, 412-420. doi:10.1016/j.chiabu.2008.09.013

Bockers, E., Roebke, S., Michael, L., Renneberg, B., \& Knaevelsrud, C. (2014). Risk recognition, attachment anxiety, self-efficacy, and state dissociation predict revictimization. PLOS One, 9, n.p. doi: 10.1371/journal.pone.0108206

Boillat, C., Schwab, N., Stutz, M., Pflueger, M. O., Graf, M., \& Rosburg, T. (2017). Neuroticism as a risk factor for child abuse in victims of childhood sexual abuse. Child Abuse \& Neglect, 68, 44-54. doi: 10.1016/j.chiabu.2017.03.018

Briere, J. N., \& Elliot, D. M. (1994). Immediate and long-term impacts of child sexual abuse. Sexual Abuse of Children, 4, 54-69.

Canli, T. (2004). Functional brain mapping of extraversion and neuroticism: Learning from individual differences in emotion processing. Journal of Personality, 72, 1105-1132 
Carter, J. C., Bewell, C., Blackmore, E., \& Woodside, D. B. (2006). The impact of childhood sexual abuse in anorexia nervosa. Child Abuse \& Neglect, 30, 257-269. doi:10.1016/j.chiabu.2005.09.004

Costa Jr., P. T., \& McCrae, R. R. (1986). Clinical assessment can benefit from recent advances in personality psychology. American Psychologist, 41, 1001-1003.

Costa Jr., P. T., \& McCrae, R. R. (1987). Neuroticism, somatic complaints, and disease: Is the bark worse than the bite? Journal of Personality, 55, 299-316.

Costa Jr., P. T., \& McCrae, R. R. (1992). Normal personality assessment in clinical practice: The NEO Personality Inventory. Psychological Assessment, 4, 5-13.

Costa Jr., P. T., McCrae, R. R., \& Dye, D. A. (1991). Facet scales for agreeableness and conscientiousness: A revision of the NEO Personality Inventory. Personality and Individual Differences, 12, 887-898. doi: 10.1016/0191-8869(91)90177-D

Costa, P. T., \& McCrae, R. R. (1995). Domains and facets: Hierarchical personality assessment using the Revised NEO Personality Inventory. Journal of Personality Assessment, 64, 2150.

Daigneault, I., Hebert, M., \& McDuff, P. (2009). Men's and women's childhood sexual abuse and victimization in adult partner relationships: A study of risk factors. Child Abuse and Neglect, 33, 638-647. doi: 10.1016/j.chiabu.2009.04.003

DeYoung, C. G., Quilty, L. C., Peterson, J. B., \& Gray, J. R. (2014). Openness to experience, intellect, and cognitive ability. Journal of Personality Assessment, 96, 46-52. doi: $10.1080 / 00223891.2013 .806327$ 
Dilorio, C., Hartwell, T., \& Hansen, N. (2002). Childhood sexual abuse and risk behaviors among men at high risk for HIV infection. American Journal of Public Health, 92, 214219.

Dube, S. R., Anda, R. F., Whitfield, C. L., Brown, D. W., Felitti, V. J., Dong, M., \& Giles, W. H. (2005). Long-term consequences of childhood sexual abuse by gender of victim. American Journal of Preventative Medicine, 28, 430-438. doi: 10.1016/j.amepre.2005.01.015

Dudeck, M., Spitzer, C., Stopsack, H. J., \& Barnow, S. (2007). Forensic inpatient male sexual offenders: The impact of personality disorder and childhood sexual abuse. The Journal of Forensic Psychiatry \& Psychology, 18, 494-506. doi : 10.1080/14789940701491495

Fergusson, D. M., Horwood, L. J., \& Lynskey, M. T. (1996). Childhood sexual abuse and psychiatric disorder in young adulthood: II. Psychiatric outcomes of childhood sexual abuse. Journal of the American Academy of Child and Adolescent Psychiatry, 34, 13651374. doi: 10.1097/00004583-199610000-00024

Fergusson, D. M., Horwood, L. J., \& Lynskey, M. T. (1997). Childhood sexual abuse, adolescent sexual behaviors, and sexual revictimization. Child Abuse and Neglect, 21, 789-803.

Finkelhor, D. (1979). Sexually victimized children. New York: Free Press

Finkelhor, D. (1984). Child sexual abuse: Challenges facing child protection and mental health professionals. In E. Ullmann \& W. Hilweg (Eds.), Childhood and trauma: Separation, abuse, war (pp. 101-115). New York: Ashgate Publishing. 
Finkelhor, D., \& Browne, A. (1985). The traumatic impact of child sexual abuse: a conceptualization. American Journal of Orthopsychiatry, 55.

Fossati, A., Kruger, R. F., Markon, K. E., Borroni, S., \& Maffei, C. (2013). Reliability and validity of the Personality Inventory for DSM-5 (PID-5): Predicting DSM-IV personality disorders and psychopathy in community-dwelling Italian adults. Assessment, 20, 689708.

Fossati, A., Somma, A., Borroni, S., Markon, K. E., \& Krueger, R. F. (2017). The Personality Inventory for DSM-5 Brief Form: Evidence for reliability and construct validity in a sample of community-dwelling Italian adolescents. Assessment, 24, 615-631.

Gidycz, C. A., McNamara, J. R., \& Edwards, K. M. (2006). Women's risk perception and sexual revictimization: A review of the literature. Aggression and Violent Behavior, 11, 441456. doi:10.1016/j.avb.2006.01.004

Gleason, K. A., Jensen-Campbell, L. A., \& Richardson, D. S. (2004). Agreeableness as a predictor of aggression in adolescence. Aggressive Behavior, 30, 43-61. doi: 10.1002/ab. 20002

Gore, W. L. \& Widiger, T. A. (2013). The DSM-5 dimensional trait model and five-factor model of general personality. Journal of Abnormal Psychology, 122, 816-821.

Graziano, W. G., \& Tobin, R. N. (2002). Agreeableness: Dimension of personality or social desirability artifact. Journal of Personality, 70, 695-728. 
Griffith, J. W., Zinbarg, R. E., Craske, M. G., Mineka, S., Rose, R. D., Waters, A. M., \& Sutton, J. M. (2010). Neuroticism as a common dimension in the internalizing disorders. Psychological Medicine, 40, 1125-1136. doi:10.1017/S0033291709991449.

Gunthert, C. K., Cohen, L. H., \& Armeli, S. (1999). The role of neuroticism in daily stress and coping. Journal of Personality and Social Psychology, 77, 1087-1100. doi: 0022$3514 / 99 / \mathrm{S} 3.00$

Harden, K. P., Carlson, M. D., Kretsch, N., Corbin, W. R., \& Fromme, K. (2015). Childhood sexual abuse and impulsive personality traits: Mixed evidence for moderation by DRD4 genotype. Journal of Research in Personality, 55, 30-40. doi: 10.1016/j.jrp.2014.12.005

Jensen-Campbell, L. A., \& Graziano, W. G. (2001). Agreeableness as a moderator of interpersonal conflict. Journal of Personality, 69, 323-362.

John, O. P., Robins, R. W., \& Pervin, L. A. (2008). Handbook of personality: Theory and research. New York: The Guilford Press.

Johnson, G. J., Cohen, P., Brown, J., Smailes, E. M., \& Bernstein, D. P. (1999). Childhood maltreatment increases risk for personality disorders during early adulthood. Archives of General Psychiatry, 56, 600-606.

Kendler, K. S., Bulik, C. M., \& Silberg, J. (2000). Childhood sexual abuse and adult psychiatric and substance use disorders in women: An epidemiological and cotwin control analysis. Archive of General Psychiatry, 57, 953-959. 
Kendler, K. S., Kuhn, J., \& Prescott, C. A. (2004). The interrelationship of neuroticism, sex, and stressful life events in the prediction of episodes of major depression. American Journal of Psychiatry, 161, 631-636.

Krabbendam, L., Janssen, I., Bak, M., Bijl, R. V., de Graad, R., \& van Os, J. (2002). Neuroticism and low self-esteem as risk factors for psychosis. Social Psychiatry and Psychiatric Epidemiology, 37, 1-6.

Krueger, R. F., Derringer, J., Markon, K. E., Watson, D., \& Skodol, A. E. (2013). The Personality Inventory for DSM-5 Brief Form (PID-5-BF). American Psychiatric Association.

Loehlin, J. C., McCrae, R. R., Costa Jr., P. T., \& John, O. P. (1998). Heritabilities of common and measure-specific components of the Big Five personality factors. Journal of Research in Personality, 32, 431-453.

Loiselle, M., \& Fuqua, W. R. (2007). Alcohol's effects on women's risk detection in a date-rape vignette. Journal of American College Health, 55, 261-266.

Marx, B. P. \& Gross, A. M. (1995). Date rape: An analysis of two contextual variables. Behavior Modification, 19, 451-463.

McCrae, R. R. (1993). Openness to experience as a basic dimension of personality. Imagination, Cognition, and Personality, 13, 39-55.

McLean, L. M. \& Gallop, R. (2003). Implications of childhood sexual abuse for adult borderline personality disorder and complex posttraumatic stress disorder. American Journal of Psychiatry, 160, 369-371. 
Meier, B. P., \& Robinson, M. D. (2004). Does quick to blame mean quick to anger? The role of agreeableness in dissociating blame and anger. Personality and Social Psychology Bulletin, 30, 856-867. doi: 10.1177/0146167204264764

Moran, P., Coffey, C., Chanen, A., Mann, A., Carlin, J. B., \& Patton, G. C. (2011). Childhood sexual abuse and abnormal personality: A population based study. Psychological Medicine, 41, 1311-1318. doi:10.1017/S003329171000178

Noll, J. G., Horowitz, L. A., Bonanno, G. A., Trickett, P. K., \& Putnam, F. W. (2003). Revictimization and self-harm in females who experienced childhood sexual abuse: Results from a prospective study. Journal of Interpersonal Violence, 18, 1452-1471. doi: $10.1177 / 0886260503258035$

Ogata, S. N., Silk, K. R., Goodrich, S., Lohr, N. E., Westen, D., \& Hill, E. M. (1990). Childhood sexual and physical abuse in adult patients with borderline personality disorder. The American Journal of Psychiatry, 147, 1008-1013.

Pavot, W., Diener, E., \& Fujita, F. (1990). Extraversion and happiness. Personality and Individual Differences, 11, 1299-1306.

Porter, K. E., Koch, E. I., Saules, K., \& Sexton, M. B. (2015). The impact of sexual assault history on perceived consequences of risky dating scenarios. Acta Psychopathologica, 1, 1-9. doi: 10.4172/2469-6676.10004

Risin, L., \& Koss, M. (1987). The sexual abuse of boys. Journal of Interpersonal Violence, 2, 309. 
Roberts, S. J., Reardon, K. M., \& Rosenfeld, S. (1999). Childhood sexual abuse: Surveying its impact on primary care. AWHONN Lifelines, 3, 39-45.

Roberts, B. W., Chernyshenko, O. S., Stark, S., \& Goldberg, L. R. (2005). The structure of conscientiousness: An empirical investigation based on seven major personality questionnaires. Personal Psychology, 58, 103-139.

Senn, T. E. \& Carey, M. P. (2010). Child maltreatment and women's adult sexual risk behavior: Childhood sexual abuse as a unique risk factor. Child Maltreatment, 15, 324-335. doi: $10.1177 / 1077559510381112$.

Soler-Baillo, J. M., Marx, B. P., \& Sloan, D. M. (2005). The psychophysiological correlates of risk recognition among victims and non-victims of sexual assault. Behavioral Research and Therapy, 43, 169-181. doi: 10.1016/j.brat.2004.01.004

Stoltenborgh, M., van Ijzendoorn, M. H., Euser, E. M., \& Bakermans-Kranenburg, M. J. (2011). A global perspective on child sexual abuse: Meta-analysis of prevalence around the world. Child Maltreatment, 16, 79-101. doi: 10.1177/1077559511403920

Terracciano, A., Lockenhoff, C. E., Zonderman, A. B., Ferrucci, L., \& Costa Jr., P. T. (2008). Personality predictors of longevity: Activity, emotional stability, and conscientiousness. Psychosomatic Medicine, 70, 621-627.

Tippett, E. C. (2018). The legal implications of the MeToo movement. Minnesota Law Review, 103, 229-302. 
Van den Akker, A. L., Prinzie, P., Dekovic, M., De Haan, A. D., Asscher, J. J., \& Widiger, T. (2013). The development of personality extremity from childhood to adolescence: Relations to internalizing and externalizing problems. Journal of Personality and Social Psychology, 205, 1038-1048. doi: 10.1037/a0034441

VanZile-Tamsen, C., Testa, M., \& Livingston, J. A. (2005). The impact of sexual assault history and relationship context on appraisal of and responses to acquaintance sexual assault risk. Journal of Interpersonal Violence, 20, 813-832. doi: 10.1177/0886260505276071

Walker, H. E., Freud, J. S., Ellis, R. A., Fraine, S. M., \& Wilson, L. C. (2017). The prevalence of sexual revictimization: A meta-analytic review. Trauma, Violence, \& Abuse, 1-14. doi: $10.1177 / 1524838017692364$

Walsh, K., DiLillo, D., \& Messman-Moore, T. L. (2012). Lifetime sexual victimization and poor risk perception: Does emotion dysregulation account for the links? Journal of Interpersonal Violence, 27, 3054-3071. doi: 10.1177/0886260512441081.

Whiffen, V. E. \& MacIntosh, H. B. (2005). Mediators of the link between childhood sexual abuse and emotional distress. Trauma, Violence, \& Abuse, 6, 24-39. doi: $10.1177 / 1524838004272543$

Widom, C. S. (1995). Victims of childhood sexual abuse and later criminal consequences. National Institute of Justice: Research in Brief.

Witte, T. H., \& Kendra, R. (2010). Risk recognition and intimate partner violence. Journal of Interpersonal Violence, 25, 2199-2216. doi: 10.1177/0886260509354880 
Wonderlich, S. A., Crosby, R. D., Mitchell, J. E., Roberts, J. A., Haseltine, B., DeMuth, G., \& Thompson, K. M. (2000). Relationship of childhood sexual abuse and eating disturbance in children. Journal of the American Academy of Child and Adolescent Psychiatry, 39, $1277-1283$. 


\section{APPENDIX A: INFORMED CONSENT}

\section{PLEASE READ THIS DOCUMENT CAREFULLY. SIGN YOU NAME BELOW ONLY IF YOU AGREE TO PARTICIPATE. YOUR SIGNATURE IS REQUIRED FOR PARTICIPATION. YOU MUST BE 18 YEARS OF AGE TO PARTICIPATE.}

\section{Description of the Study:}

This study will ask you to select dating profiles of interest to you, complete a brief online dating profile, complete questionnaires online, and read a vignette about two individuals who meet online dating.

Nature of Participation: You will spend approximately 45 - 60 minutes completing the tasks.

Purpose of the Study: You will be provided with an explanation of the study following the last task.

Possible Risks: When completing the questionnaires, you may come across a question or group of questions that you find unpleasant or upsetting. For instance, a few questions may cause you to think about painful past experiences and/or negative emotional states. You will be asked to provide confidential information about yourself, including information pertaining to past sexual experiences and drug use. In the event that you do become upset, a research assistant will remind you that you can withdraw from the study. If needed, a researcher will take you to the Student Counseling Services building. Researchers will provide you with a list of local resources who can help you. Although code numbers will be used, there is also a slight risk of loss of confidentiality. You will provide a brief online dating profile that may have identifying information, however, that specific information will be deleted at the conclusion of the study.

Possible Benefits: This study will allow participants to contribute to the understanding of online dating and relationship development among young adults as an outcome of past experiences and individual characteristics. If you desire to be informed about the outcome of this study, you can contact the researcher through the information listed below.

Compensation for your time: You will receive extra credit in a psychology course through the SONA system. You will receive extra credit simply by virtue of coming to your appointment; you are free to withdraw your participation at any time without penalty.

Confidentiality: Your study materials have been assigned a code number that will protect your identity. All data will be kept in secured files, in accord with the standards of the University, Federal regulations, and the American Psychological Association. Finally, it is no individual person's responses that interest us; we are studying people in general.

Opportunities to Question: Any technical questions about this research may be directed to Dr. Marla Reese-Weber at 438-3743. Any questions regarding your rights as a research participant or research-related injuries may be directed to ISU's Office of Research Ethics and Compliance (309) 438-2529.

Opportunities to Withdraw: If you decide now or at any point to withdraw this consent or stop participation, you are free to do so at no penalty to yourself. You are free to skip specific questions and continue participating at no penalty.

Opportunities to be Informed of Results: In all likelihood, the results will be fully available around the summer of 2019. If you wish to be told the results of this research, please contact Dr. Marla Reese-Weber at 438-3743. She will either meet with you to discuss the results or direct you to a copy of the results. In addition, there is a chance that the results from this study will be published in a scientific psychology journal, which would be available in many libraries. In such an article, participants would be identified in general terms such as "college students."

I consent to participate in this study. 
Print name here 


\section{APPENDIX B: DEMOGRAPHIC QUESTIONNAIRE}

Gender:

1. Male

2. Female

3. Other (e.g. transgender, gender queer), please specify

Sexual Orientation

1. Heterosexual

2. Homosexual/Gay/Lesbian

3. Bisexual

4. Pansexual

5. Other, please specify

Age:

Year in school

1. Freshman

2. Sophomore

3. Junior

4. Senior

5. Graduate-Master's

6. Graduate- Doctorate

7. Other, please specify

Ethnic Background:

1. White/Caucasian

2. Black/African-American

3. Hispanic/Latino

4. Asian-American

5. Middle Eastern/North African

6. Mixed Ethnicity

7. Prefer not to answer

8. Other, please specify:

Current living arrangements

1. Live with parents

2. Live in the residence halls

3. Live in an apartment alone

4. Live in an apartment with friends

5. Live in an apartment with romantic partner

6. Other, please specify 
Relationship Status:

1. Single

2. Dating someone

3. Living with significant other

4. Married

5. Divorced

6. Separated

7. Widowed

8. Other (please specify)

Family Status:

1. Biological/adopted parents are currently married (skip next question)

2. Biological/adopted parents are currently divorced

3. Single Parent

4. Other, please specify

Following the divorce of your biological/adopted parents, with whom did you live the majority of the time?

1. Mother

2. Mother and Step-father

3. Father

4. Father and Step-mother

5. Other, please specify

Mother/stepmother's Highest Education:

1. Some high school, but no degree

2. High School degree

3. Two years college

4. Four years college (Bachelor's degree)

5. Graduate Degree (Master's degree or higher)

Father/stepfather's Highest Education:

1. Some high school, but no degree

2. High School degree

3. Two years college

4. Four years college (Bachelor's degree)

5. Graduate Degree (Master's degree or higher)

How many biological/adopted/step-siblings do you have? 


\section{APPENDIX C: DEBRIEFING STATEMENT}

The purpose of the study is to examine if past sexual experiences, personality characteristics, and feelings of rejections are related to one's ability to recognize risky situations. We expect that individuals recently rejected in interpersonal contexts will have a delayed response in recognizing risk in interpersonal interactions compared to individuals who have not been recently rejected.

Please remember that your responses are confidential and all data will be kept in secure files. Because the study is not really assessing online dating profiles, the online dating profile you created will be deleted following the conclusion of the study. Hence, not identifying information will be connected to your questionnaire data.

If after completing this study you are upset or would like to discuss your experience, you may contact Illinois State University's Student Counseling Services at (309) 438-3655 or http://counseling.illinoisstate.edu. You can also contact the PATH crisis center for a referral at (309) 8274005 or $1-800-570-7284$.

If you have any questions regarding this study or would like more specific information regarding this study, please contact Dr. Marla Reese-Weber at (309) 438-3743 or mjreese@ilstu.edu. You may also contact the graduate students conducting this study to satisfy a Master's Thesis in psychology, Jordan Marshall at jemars1@ilstu.edu or Emily Harms, at emharms@ilstu.edu. Any questions regarding your rights as a research participant or research-related injuries may be directed to ISU's Office of Research Ethics and Compliance (309) 438-2529.

Please do not share the purpose or expectation of this study with other classmates, as we may continue to do research in the future. Thank you again for your participation! Good luck with the rest of your semester! 


\section{APPENDIX D: VIGNETTE}

\section{Scene 1}

M: Hi cutie!

W: Hello :)

M: I saw you go to ISU. So do I. What do you study?

$\mathrm{W}$ : Working on getting my degree in business administration. What about you?

M: Thinking about declaring a bio major

W: Oh, that's cool. Why do you want to do that?

M: I like science. But let's not talk about school :p What are some things you like to do?

$\mathrm{W}$ : I guess in my free time I like to go out with my friends.

M: Sweet. You look really familiar. Have we had a class together?

W: I was thinking the same thing! Maybe it was speech last year?

M: That's it! So, do you wanna go out sometime?

Are you comfortable in this interaction?

Would you continue this interaction?

\section{Scene 2}

W: Maybe. I'll have to see when I'm free

M: You're so beautiful.

W: Thanks. So, what did you think of the personal history presentation we had to give for class?

M: Public speaking isn't really my thing but I would have loved to hear yours. Guess you'll just have to fill me in when we hang out. ;)

W: Haha I'm not sure my speech was worth reliving

M: If I got to look at you I'm sure any speech would be worth listening to.

W: Haha, yeah okay.

M: So what are you doing tonight?

Are you comfortable in this interaction?

Would you continue this interaction?

\section{Scene 3}

W: I'm getting ready to go out with my friends.

M: I bet you look so fine. Maybe we can meet up later ;)

W: Ha, we're having a girls' night. I'm not sure they'd be into me inviting a guy along tonight but maybe another time

M: You should send me a pic so I can see how good you look.

W: I usually like to get to know guys better before I give out pics

M: Guess we'll just have to get to know each other then :)

$\mathrm{W}$ : Haha I suppose that is one solution. :p

M: Exactly! :) So we should hang out tonight. Where will you and your friends be going?

Are you comfortable in this interaction? 
Would you continue this interaction?

\section{Scene 4}

W: I'm not sure yet. We don't have concrete plans.

M: You gotta let me know so we can have fun tonight :) Can I get your ChatSnap?

$\mathrm{W}$ : My username is collegegrlxoxo add me.

M: Sweet! I just added you.

*Conversation ends and $\mathrm{W}$ meets friends at bar and gets the following message on ChatSnap* M: So, where did you and your friends decide to go?

Are you comfortable in this interaction?

Would you continue this interaction?

\section{Scene 5}

W: We're uptown.

M: I see on my ChatSnap map that you're at the bar. I'll be there soon.

W: Oh, uhhh... Okay.

*guy shows up at the same bar*

* guy approaches girl in person*

M: Hey there. You look fine tonight.

$\mathrm{W}$ : *blushes* Oh. Thanks.

M: Let's dance

W: I'm kinda hanging out with my friends right now. I don't want to ditch them.

M: Come on. I want to get closer to you.

Are you comfortable in this interaction?

Would you continue this interaction?

\section{Scene 6}

W: Okay, fine.

*guy and girl dance together*

M: Come closer

W: Actually, I'm going to get another drink.

M: I'll come with you.

*they get another drink and then go back to dancing*

M: You're so hot. And you're such a good dancer.

W: Thanks. I wonder where my friends are.

M: Who cares. We're having such a good time together.

W: Wow, it's getting really hot in here. I think I'm going to step outside.

M: I agree. I'll come with you. 
Are you comfortable in this interaction?

Would you continue this interaction?

Scene 7

*they go outside*

W: Actually, I think maybe my friends went home already. I'm not really feeling well so I think

I'm going to head out.

M: Are you okay? I'll walk you home.

W: Are you sure? You don't really need to do that.

M: Of course, wouldn't want you walking alone at night.

Are you comfortable in this interaction?

Would you continue this interaction?

\section{Scene 8}

W: Well... Okay, thanks

*guy grabs girls hand and walks her home*

W: Well, this is my place. Thanks for walking me home.

M: No problem. Actually, do you mind if I come inside for a second?

Are you comfortable in this interaction?

Would you continue this interaction?

\section{Scene 9}

W: Oh, um I think my roommates are home.

M: I don't see any lights on. I think we'll be fine *winks*

W: Alright, I guess that would be okay for a little while.

*they walk into her apartment*

M: I like your apartment.

W: Thanks!

M: The part I like most is that we're here alone.

W: Yeah.. I think my roommates will be home soon.

M: Let's sit down on the couch.

Are you comfortable in this interaction?

Would you continue this interaction?

Scene 10 
W: Umm... sure I'll stream a movie

* the two sit on the couch together*

M: I'm so glad we ran into each other tonight.

*guy kisses girl*

* guy moves closer to girl and kisses her more, she kisses back*

M: You're a great kisser.

W: Thanks. I'm going to go ahead and start the movie

*the movie starts*

M: You are so beautiful.

*guy kisses girl*

M: I am so turned on.

Are you comfortable in this interaction?

Would you continue this interaction?

\section{Scene 11}

*guy unbuttons girl's shirt*

*she pulls back*

W: Whoa, let's slow down.

M: *moans* Come on ...

*he continues to kiss her*

W: I hardly know you. We should just watch the movie.

M: I am so into you. I want to make you feel so good.

Are you comfortable in this interaction?

Would you continue this interaction?

\section{Scene 12}

*Guy kisses girl and begins to rub her breasts*

M: You feel so great

W: I'm not ready for this yet

M: But I'm so turned on

\section{Are you comfortable in this interaction?}

Would you continue this interaction?

\section{Scene 13}

*guy unbuttons girl's pants*

W: Okay ... seriously... please stop. 
M: But this feels so good. We shouldn't stop now

Are you comfortable in this interaction?

Would you continue this interaction? 


\section{APPENDIX E: STUDY PROCEDURE}

*Participant arrives at study session.*

Researcher (R): "Hi, are you _ _ here for the Online Dating study?"

Participant (P): "Yes."

R: "Alright, so I'd like to start by giving you a rundown of how the study will go, and then have you look over the consent forms. The study will take about 30-45 minutes to complete. The purpose of the study is to test an algorithm for matching people on online dating sites. There are three main parts to this study.

1. you will read and select dating profiles as well as write a bio for yourself

2. you will answer some questionnaires

3. you will read a scenario about a online dating interaction and answer some questions."

"Here's the informed consent form."

*Researcher hands informed consent form to participant.*

"Please read that over, let me know if you have any questions, and then, if you agree to participate, go ahead and sign it."

*Participants reads informed consent form and signs.*

R: "Alright, before we move forward, I just wanted to highlight that your participation is voluntary and you are free to stop participating in the study at any time without any penalty towards you."

R: *Starts Qualtrics survey.*

"Before we start, I want to reassure you that all of the instructions I give you will also be on the computer as you go through the tasks."

"Okay, so I'll have you start by viewing the profiles and selecting which individuals you would hypothetically be interested in talking with. There will be 10 profiles that contain a picture and a brief bio. You need to select 5 you'd be interested in meeting if you were really considering using an online dating site/app."

After that go ahead and click the next button. It will take you to the section where you fill out the bio the way you would for an online dating profile. You will have 500 characters to convey whatever you want about yourself. I want to reiterate from the informed consent form that this information will not be connected to your name so the researchers will not know whose bio belongs to you."

"When you're finished with your bio, click the next button and then you will complete the questionnaires."

"Do you have any questions about these first two parts?"

*If yes, research assistant answers questions.*

R: "Okay, I will be waiting in the hallway. Let me know when you have finished the questionnaires."

*Participant completes questionnaires* 
R: Okay, now that all your information has been submitted, let's who's a match with you.

*Researcher randomly selects rejection or nonrejection condition.

- If rejection condition, "looks like you 2 matches of 10 , only one of those is one that you selected as your $5 . "$

- If non-rejection condition, "looks like you have 8 matches of 10 , four of those are ones that you selected as your 5."

R: "Okay, so for this next part you are going to read through a scenario of two people meeting online. The story is broken up into sections so that every so often it stops to ask you some questions. It is always going to ask you if you would be comfortable in this situation and if you were in this situation would you continue with the interaction. Again, try to imagine that you are the woman in the situation and how you would feel and what you would do, if you were really considering using an online dating site. Do you have any questions?"

*If yes, research assistant answers questions.*

R: "I'll be in the hall so come and get me when you are finished."

*Researcher leaves participant to go through vignette.*

*Participant completes vignette and notifies research assistant.*

R: "We are now done with the study." Then, ask the following questions:

What did you think of the study?

What did you think of questionnaires you completed today?

Were the questions familiar?

Do you have any ideas about how those questionnaires and activities might be related to what you did today?

Was any part of the study upsetting to you?"

*After discussing participant's responses with him/her, tell the participant*,

"We are interested in finding out how individual differences might be related to different reactions during dating or risky situations. Individual differences include personal history, personality characteristics, and reactions to rejection. To do this, we asked you to complete several questionnaires but we also tricked you. There is no algorithm we are testing. We had you select profiles and create a bio for yourself so that we could randomly assign you to the rejection or non-rejection condition. Those assigned to the rejection group were told they only had 2 matches and those assigned to the non-rejection group were told they had 8 matches. We will be examining how rejection might influence perception of a potentially risky situation like the one in the vignette that you read.

Does that make sense? Do you have any questions for me?"

*If yes, research assistant answers questions.* 
$\mathrm{R}$ : "Here is a debriefing statement that also explains the study and provides some contact information if you have questions about the study or experienced distress following this procedure."

* Hands them debriefing statement

R: "We need to ask one more thing of you: Could you please refrain from telling your friends and classmates about this study? We have many more participants to test in this study and we want all of them to experience it with fresh eyes. Could you do that for us?"

R: "Thank you for participating in this study. Your extra credit should be posted to SONA within the next few days." 